\title{
Dissociated disorders of speaking and writing in aphasia
}

\author{
A. B A S S A, TABORELLI, A N D. A. V I G N O L O \\ From the Centro di Neuropsicologia, Clinica Neurologica, Milan, Italy
}

SUMMARY Of 500 left brain-damaged patients with educational level above elementary school investigated with a standard quantitative battery for dissociation between oral and written expression, speech was found to be selectively impaired in seven (three with "pure anarthria," two with anarthria in the context of Broca's aphasia, and two with fluent aphasia with remarkable sparing of writing), and writing in another seven (two with "pure" agraphia, two with "agraphia with mild alexia," and three with "agraphia with mild fluent aphasia.") The nature of three conditions (pure anarthria, fluent aphasia with sparing of writing, and pure agraphia) is discussed, with evidence of a selective association between pure agraphia and lesions of the upper left parietal lobule.

The classic forms of aphasia showing dissociation between oral and written expression are still controversial in many respects. Anarthria, where oral expression is selectively impaired, is generally accepted as an independent entity, but its frequency is a matter of discussion-ranging from $4 \%$ of all aphasias, as recently maintained by Tissot et al. (1970), to exceedingly rare as believed by Souques (1928) who declared that he had collected only nine convincing cases in 20 years. As to pure agraphia, in which writing is altered selectively, its very existence as an independent syndrome is questioned. Chédru and Geschwind (1972b) have described isolated agraphias in studies of confusional states and have suggested that many, and perhaps the majority, of cases of isolated agraphia in the literature are examples of this mechanism.

The aim of our study was twofold: in the first place, we wished to ascertain the presence and the incidence of a conspicuous dissociation between oral and written expression in a large sample of left brain-damaged patients with language disorders; in the second place, we wished to verify to what extent such dissociated syndromes corresponded to the classic forms of anarthria and pure agraphia.

Supported by a CNR grant. Presented at the Neuropsychological Symposium, Roc Amadour, France, June 1976.

Address for reprint requests: Professor L. A. Vignolo, Clinica Neurologica, Padiglione Ponti, Via F. Sforza 35, Milan 20122, Italy.

Accepted 5 January 1978

\section{Materials and methods}

We have analysed the records of 500 consecutive patients with left hemisphere damage, referred to our Aphasia Unit from 1962 to 1975 for language evaluation, and examined by means of a standard language battery. Only patients with six or more years of schooling were considered, since at lower educational levels writing may be very poor even in normal adults and, as a consequence, its disorders cannot be reliably assessed. Patients with left handedness, bilateral lesions, or incomplete records were excluded from the study.

This group of 500 patients constituted a fairly representative sample of left brain-damaged patients with educational level above elementary school, as it included both inpatients and outpatients suffering from lesions of different aetiologies (mainly vascular), examined at different time intervals from the onset of the cerebral symptoms.

The standard aphasia examination included 16 subtests, which afforded a quantitative score for the main aspects of language behaviour, as well as an accurate recording of the type of errors in speech and writing (see Tables 1 and 2). The results of the nonverbal scale of the WAIS were available for all patients, as well as those of tests for the apraxias (oral: imitation of buccofacial gestures; ideomotor: imitation of intransitive upper limb gestures; constructional: copying geometrical drawings; and apraxia of use: showing the use of actual objects). Acalculia, finger 
agnosia, and right-left discrimination were not assessed systematically.

The dissociation between oral and written expression was defined on the basis of the scores obtained on the following four subtests: (a) oral description of an event; (b) oral naming of 20 pictures of objects; (c) writing a letter to a relative or friend; (d) written naming of 20 pictures, the same as used for oral naming.

In tests $a$ and $c$ communication was scored 0 (none), 1 (poor), 2 (sufficient), 3 (good). In tests $b$ and $d$ communication was scored as percentage of correct naming responses (ranging 0 to 100 points).

Oral expression was judged to be selectively impaired (in comparison to written expression) whenever the oral description score was 0 , while the writing a letter score was 2 or more, the oral naming score was less than 35 and was exceeded by the written naming score by 35 points or more.

These criteria were of course reversed for defining a selective impairment of written expression.

\section{Results}

A clear dissociation between oral and written expression, as defined in this study, was found in 14 of 500 patients. Speech was selectively impaired in seven patients and writing in seven. In the former group, three patients showed the classical syndrome of "pure anarthria," two had a severe anarthria in the context of Broca's aphasia, and two were fluent aphasics with remarkably good writing. Within the latter group, the writing defect was quite isolated from other language disorders in two patients (thus realising the picture of socalled "pure agraphia)," while it was associated with slight, but definite reading disorders in two other patients (labelled "agraphia with mild alexia"), and with slight oral language disorders of the nonfluent type in three patients (labelled "agraphia with mild fluent aphasia"). The main characteristics of patients in each group, shown in Table 1 and 2, will be described.

\section{PATIENTS WITH SELECTIVE IMPAIRMENT OF ORAL EXPRESSION (TABLE 1)}

The three patients with pure anarthria showed a common feature, consisting of a combination of phonemic distortions and articulation defects, which disrupted speech output, no matter how elicited. In addition to oral description and naming which were poor by definition, repetition and reading aloud were also severely impaired. By contrast, all other aspects of language investigated by the standard aphasia battery were preserved. In particular, writing to command, to dictation, and to copy were normal or minimally defective. Writing a letter was perfect in patients 01 and 03, while it showed only two errors in patient 02 . Contrary to the observation of Alajouanine et al. (1939), writing in our cases was never agrammatic. Transcription from print to script was easy and flawless. Auditory verbal comprehension was excellent, even when examined by such an exacting tool as the Token Test (patients 01 and 03 scored 37 out of 39, and patient 02,31 out of 39). None of these patients were clinically demented and, indeed, the IQs obtained on the WAIS nonverbal subtests ranged higher than expected of patients of comparable educational level, suffering from a left hemisphere lesion and aphasia.

Differential features were also observed. In one patient $(01)$ the disorder was confined strictly to oral expression from the very onset of the illnessa cerebrovascular accident. Anarthria presented as an abrupt, total suppression of speech; this lasted for about two days, then evolved to rare utterances and, finally, to a "syndrome of phonetic disintegration" (Alajouanine et al., 1939) that gradually disappeared within a few days. The motor defect was limited to a mild right lower facial weakness. There was no oral apraxia. The patient was perfectly alert throughout and, from the very beginning, he tried to overcome his inability to communicate through speech by resorting spontaneously to paper and pencil. In our experience, this behaviour is never found in Broca's aphasia.

The other two patients ( 02 and 03 ) were examined long after the stroke; therefore, the possibility that pure anarthria here was the residual symptom of an ordinary Broca's aphasia cannot be ruled out. Both patients had severe oral apraxia. Speech in 02 showed a "syndrome of phonetic disintegration" with paralytic dysarthria. Phonemes were omitted, substituted, or misplaced; articulation was slurred; oral outflow was scarce, but relatively rapid; the patient tended to talk rather fast and occasionally produced short runs resembling phonemic jargon. Self-pacing was possible and resulted in a slower, more understandable speech. This aspect of pure anarthria has been observed before, for example, by Tissot et al. (1970), who have pointed out that the extreme slowing of the rate of speech, which is typical of Broca's aphasia, is not an obligatory feature of isolated anarthria.

In patient 03 , phonemic distortions and slurred articulation were overshadowed by a concomitant weakness of phonation: words were uttered in an almost imperceptible whisper, which often prevented the accurate recording of errors. Voluntary 
Table 1 Clinical and neuropsychological features of patients with poorer speech than writing

\begin{tabular}{|c|c|c|c|c|c|c|c|}
\hline \multirow[b]{2}{*}{ Patient number } & \multicolumn{3}{|c|}{ Pure anarthria } & \multicolumn{2}{|c|}{ Broca's aphasia } & \multicolumn{2}{|c|}{ Fluent aphasia } \\
\hline & 01 & 02 & 03 & 04 & 05 & 06 & 07 \\
\hline Age (yr) & 67 & 69 & 52 & 35 & 34 & 69 & 24 \\
\hline Years of schooling & 13 & 17 & 17 & 6 & 7 & 8 & 13 \\
\hline \\
\hline $\begin{array}{l}\text { aetiology } \\
\text { length of illness }\end{array}$ & $3 \mathrm{~d}$ & $7 \mathrm{mo}$ & $24 \mathrm{mo}$ & $7 d$ & $14 \mathrm{mo}$ & $3 \mathrm{mo}$ & $\begin{array}{l}\mathrm{N}(\mathrm{Abl}) \\
13 \mathrm{mo}\end{array}$ \\
\hline \multicolumn{8}{|l|}{ Neurological defects } \\
\hline MD & $t^{*}$ & $t^{*}$ & + & + & + & \pm & - \\
\hline SD & - & - & - & - & - & - & - \\
\hline VFD & - & - & - & - & - & - & + \\
\hline \multicolumn{8}{|l|}{ Apraxias } \\
\hline BFA & - & + & + & + & + & - & - \\
\hline IMA & - & - & - & - & - & - & - \\
\hline $\mathbf{A U}$ & - & - & - & - & - & - & - \\
\hline $\mathbf{C A}$ & - & - & - & - & - & - & - \\
\hline WAIS QIP & 99 & 111 & 106 & 63 & 99 & 117 & 97 \\
\hline \multicolumn{8}{|l|}{ Oral expression } \\
\hline D & 0 & 0 & $\mathbf{0}$ & $\mathbf{0}$ & 0 & $\mathbf{0}$ & $\mathbf{0}$ \\
\hline $\mathbf{N}$ & 20 & 35 & $\mathbf{0}$ & 10 & 30 & 20 & 35 \\
\hline \multicolumn{8}{|l|}{ Auditory comprehension } \\
\hline words & 100 & 95 & 100 & 100 & 100 & 100 & 100 \\
\hline sentences & 100 & 95 & 100 & 80 & 100 & 95 & 85 \\
\hline \multicolumn{8}{|l|}{ Repetition } \\
\hline words & 40 & 30 & 0 & 0 & 25 & 95 & 100 \\
\hline sentences & 40 & 40 & 0 & $\mathbf{0}$ & 30 & 50 & 20 \\
\hline \multicolumn{8}{|l|}{ Written expression } \\
\hline $\mathbf{L}$ & 3 & 3 & 3 & 2 & 2 & 2 & 2 \\
\hline words & 90 & 100 & 95 & 50 & 90 & 65 & 85 \\
\hline \multicolumn{8}{|l|}{ Reading comprehension } \\
\hline words & 100 & 95 & 100 & 100 & 100 & 100 & 100 \\
\hline sentences & 100 & 100 & 100 & 50 & 100 & 100 & 100 \\
\hline \multicolumn{8}{|l|}{ Reading aloud } \\
\hline words & 30 & 50 & $\mathbf{0}$ & 0 & 30 & 95 & 95 \\
\hline sentences & 15 & 40 & $\mathbf{0}$ & 0 & 33 & 100 & 100 \\
\hline \multicolumn{8}{|l|}{ Dictation } \\
\hline $\begin{array}{l}\text { words } \\
\text { sentences }\end{array}$ & 90 & 100 & $\begin{array}{r}100 \\
65\end{array}$ & 60 & 100 & $\begin{array}{l}90 \\
35\end{array}$ & $\begin{array}{l}90 \\
30\end{array}$ \\
\hline \multicolumn{8}{|l|}{ Copying } \\
\hline words & 100 & 100 & 100 & 100 & 100 & 100 & 100 \\
\hline $\mathbf{B l} / \mathbf{s l}$ & 100 & 100 & 100 & 100 & 100 & 100 & 100 \\
\hline
\end{tabular}

The language examination scores are expressed in percentages of correct responses, except $D$ (Oral Description) and $L$ (Writing a Letter) scores which range from 0 to $3 ; \mathrm{V}=$ vascular; $\mathrm{N}=$ neoplastic; $\mathrm{Abl}=$ ablation. $\mathrm{d}=$ days; $\mathrm{mo}=$ months; $\mathrm{MD}=$ right motor defect; $\mathrm{SD}=$ right sensory defect; VFD = right homonymous visual field defect; BFA = buccofacial (oral) apraxia; IMA =ideomotor apraxia; $\mathbf{A U}=$ apraxia of use; $\mathbf{C A}=$ constructional apraxia; $+=$ present; $-=$ absent; ?=not tested; ${ }^{*}=$ right lower face only; $\mathrm{N}=$ naming; $\mathrm{Bl} / \mathrm{sl}=$ transcription from block letters to small handwritten letters.

efforts to increase the volume of voice were generally ineffective. Examination of the vocal cords failed to show evidence of peripheral involvement. This difficulty of phonation is reminiscent of that recorded by Alajouanine $e t$ al. (1939) in their case Louise Cha.

\section{Broca's aphasia with severe anarthria and relatively good writing}

Both patients in this category (04 and 05) differed from the preceding ones because writing, while much better than speech, was not intact. The speech disorder consisted of a typical "syndrome of phonetic disintegration" with reduction of the speech outflow, syllabic scansions, and laborious articulation. In addition to oral description and naming, repetition and reading aloud were severely inpaired (score 0). Oral apraxia and right hemiparesis were present in both cases. The disorder was recent in one patient (seven days) and longstanding in the other (14 months). The lesion was vascular in nature; its precise intrahemispheric site could not be ascertained.

Fluent aphasia with remarkably good writing Patients 06 and 07, who showed this condition, were an unexpected and most interesting finding. Speech in these patients, while perfectly fluent and without the least disorder of articulation, was severely altered by anomias, paraphasias, and circumlocutions. By contrast, writing, though not intact, was sufficiently good to fulfil the criteria of dissociation. The sites of lesions in these patients were quite comparable, as shown in the Figure: one of them (06) had undergone excision of a small, well-circumscribed tumour in the middle third of the second left temporal convolution, while in the other (07) the anterior half of the 
Table 2 Clinical and neuropsychological features of patients with poorer writing than speech

\begin{tabular}{|c|c|c|c|c|c|c|c|}
\hline \multirow[b]{2}{*}{ Patient number } & \multicolumn{2}{|c|}{ Pure agraphia } & \multicolumn{2}{|c|}{ Agraphia with mild alexia } & \multicolumn{3}{|c|}{ Agraphia with mild fluent aphasia } \\
\hline & W1 & W2 & W3 & W4 & W5 & W6 & W7 \\
\hline Age (yr) & 44 & 56 & 83 & 65 & 61 & 66 & 72 \\
\hline Years of schooling & 17 & 6 & 8 & 9 & 13 & 11 & 8 \\
\hline \multicolumn{8}{|l|}{$\begin{array}{l}\text { Lesion } \\
\quad \text { aetiology }\end{array}$} \\
\hline length of illness & $3 \frac{1}{2} \mathrm{mo}$ & $28 \mathrm{~d}$ & $2 \mathrm{mo}$ & $4 \mathrm{mo}$ & $5 \mathrm{~d}$ & $16 \mathrm{~d}$ & $20 \mathrm{~d}$ \\
\hline \multicolumn{8}{|l|}{ Neurological defects } \\
\hline MD & - & + & - & - & - & - & $t^{*}$ \\
\hline SD & - & - & + & $?$ & - & + & - \\
\hline VFD & + & - & + & - & - & - & - \\
\hline \multicolumn{8}{|l|}{ Apraxias } \\
\hline BFA & - & - & - & - & - & - & - \\
\hline IMA & - & - & - & - & ? & - & - \\
\hline $\mathrm{AU}$ & - & - & + & - & ? & - & - \\
\hline CA & - & - & - & - & $?$ & - & - \\
\hline WAIS QIP & 68 & 84 & 83 & 78 & 91 & 81 & 83 \\
\hline \multicolumn{8}{|l|}{ Oral expression } \\
\hline D & 2 & 2 & 2 & 2 & 2 & 2 & 2 \\
\hline $\mathbf{N}$ & 85 & 95 & 95 & 75 & 75 & 60 & 80 \\
\hline \multicolumn{8}{|l|}{ Auditory comprehension } \\
\hline words & 90 & 100 & 100 & 85 & 100 & 100 & 100 \\
\hline \multirow{2}{*}{\multicolumn{8}{|c|}{ Repetition }} \\
\hline & & & & & & & \\
\hline words & 100 & 95 & 100 & 100 & 100 & 85 & 85 \\
\hline sentences & 80 & 60 & 100 & 100 & 80 & 60 & 30 \\
\hline \multicolumn{8}{|l|}{ Written expression } \\
\hline L & 0 & $\mathbf{0}$ & 0 & 0 & $\mathbf{0}$ & 0 & 0 \\
\hline \multirow{2}{*}{\multicolumn{8}{|c|}{ Reading comprehension }} \\
\hline & & & & & & & \\
\hline words & 95 & 100 & 100 & 65 & 100 & 100 & 100 \\
\hline \multicolumn{8}{|l|}{$\begin{array}{l}\text { sentences } \\
\text { Reading aloud }\end{array}$} \\
\hline words & 100 & 100 & 90 & 45 & 65 & 80 & $\mathbf{0}$ \\
\hline sentences & 100 & 85 & 50 & 0 & 15 & 82 & 0 \\
\hline \multicolumn{8}{|l|}{ Dictation } \\
\hline words & 10 & 60 & 0 & 10 & 30 & 0 & 0 \\
\hline sentences & 0 & 0 & 0 & 0 & 15 & 0 & 0 \\
\hline \multicolumn{8}{|l|}{ Copying } \\
\hline $\begin{array}{l}\text { words } \\
\mathrm{B} 1 / \mathrm{sl}\end{array}$ & $\begin{array}{l}65 \\
72\end{array}$ & $\begin{array}{l}65 \\
95\end{array}$ & $\begin{array}{l}22 \\
60\end{array}$ & $\begin{array}{l}\mathbf{0} \\
\mathbf{0}\end{array}$ & $\begin{array}{r}66 \\
100\end{array}$ & $\begin{array}{l}55 \\
50\end{array}$ & $\begin{array}{l}45 \\
16\end{array}$ \\
\hline
\end{tabular}

Abbreviations and footnotes as for Table 1 except $*=$ right lower limb only.

left temporal lobe had been ablated in order to remove an angioma with satellite haematoma. Both cases, then, had lesions bordering the posterior language area from below and in front, but sparing entirely the posterior and superior marginal zones in the parietal lobe.

PATIENTS WITH SELECTIVE IMPAIRMENT OF WRITTEN EXPRESSION (TABLE 2)

In all seven patients, the defect in writing to command was, by definition, severe. In addition, writing of words and sentences to dictation was also grossly impaired. On the other hand, copying words and the transcription of isolated letters from print to script were relatively preserved, except in patients $\mathrm{W} 3$ and $\mathrm{W} 4$ with mild alexia in addition to agraphia. The quality of the writing defect was evaluated by recording presence and severity of linguistic, motor, and spatial errors, as defined by Chédru and Geshwind (1972b). It was found that all seven patients, including those with pure agraphia, had predominantly linguistic errors.
Moderate motor errors, consisting of an awkward and "trembling" handwriting (with occasional additions of a few loops and curves to letters) occurred in two patients, one with "pure agraphia" and the other with "agraphia plus alexia." Minimal spatial disorders, consisting merely of a somewhat irregular alignment of words, occurred in three patients, one in each subgroup. A more detailed analysis of the linguistic errors in the various tasks was then undertaken.

Writing to command Writing a letter was impossible in patient W1, who confined himself to tracing two capital letters ( $J, A)$, seemingly unrelated to each other, in the upper left corner of the sheet; his signature, however, was perfect. The performances of the other six patients showed a common pattern. The general arrangement of the letter-that is, the opening "Dear . ..." followed by a two or three line message, the greetings and the signature-was correct; the length of the letter was reasonable, as the total number of words (excluding the signature) ranged from 11 to 29 


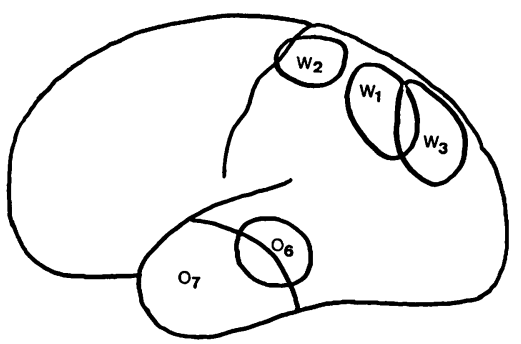

Figure Site of lesions in fluent aphasia with good writing (cases 06 and 07), pure agraphia (W1 and W2), and agraphia with mild alexia (W3).

$(\overline{\mathrm{x}}=19)$. The text consisted mainly of neologisms, among which one occasional comprehensible word could be recognised; perseveration of parts of neologisms sometimes occurred. In contrast with the text, the signature was always flawless.

On the naming task, one patient (W1) wrote isolated letters or perseverating short neologisms, four (W3, W4, W5, W7) wrote predominantly neologisms plus a few misspelled but recognisable words, and two (W2, W6) wrote exclusively misspelled words. Such misspellings were similar in quality to those encountered in writing to dictation (see below, Table 3). There were no substitutions of entire words and whenever one occasional word finding difficulty was recorded, it occurred in speech earlier than in writing. Thus, errors in writing to command were always phonemic rather than lexical. This seems to confirm the notion that the link between oral and written language is established at the phonological level.

Writing to dictation A detailed analysis of errors was made for writing to dictation of single words. Results, shown in Table 3, indicate that grapheme substitutions were the most frequent type of error, followed by omissions, while additions were rele- vant only in agraphia with mild aphasia; consonants and vowels were about equally affected, and graphemes in middle and initial position were misspelled or omitted more frequently than those in final position. A word of caution is necessary in interpreting the figures given in this Table: even in the absence of motor disorders, the individual differences and the particular characteristics of each patient's handwriting made it sometimes impossible to decipher precisely a given letter in the context of a word, so as to differentiate it from similar ones (for example, $a$ from $o, t$ from 1 , and so on). Thus, a certain degree of error was inevitable.

The locus of the lesion was known in the two patients with pure agraphia and in one patient with agraphia plus alexia (see Figure). Both patients with pure agraphia had parietal (parasagittal) lesions. Patient W1 had sustained a cerebrovascular accident and had undergone surgery with emptying of intracerebral left parietooccipital haematoma. In patient W2 a central (Rolandic) meningioma had been excised. Patient W3 with agraphia plus alexia sustained a cerebrovascular accident; the isotope brain scanning indicated that the lesion was in the upper posterior parietal-occipital area.

\section{Discussion}

The present study provides evidence that a clinically conspicuous dissociation between oral and written expression exists in a small number of left brain-damaged patients with language disorders $(1.4 \%$ in our sample), either speech or writing being specifically impaired. Among such dissociated cases, three conditions are particularly interesting - anarthria, fluent aphasia with sparing of writing, and pure agraphia.

Table 3 Analysis of performances in writing 10 single words to dictation

\begin{tabular}{|c|c|c|c|c|c|c|c|c|c|c|c|}
\hline \multirow[b]{3}{*}{ Syndrome } & \multirow[b]{3}{*}{$\begin{array}{l}\text { Patient } \\
\text { number }\end{array}$} & \multirow{2}{*}{\multicolumn{2}{|c|}{ Type of errors }} & \multicolumn{8}{|c|}{ Errors in misspelled words } \\
\hline & & & & \multicolumn{3}{|c|}{ Type } & \multicolumn{2}{|c|}{$\begin{array}{l}\text { Incorrect } \\
\text { grapheme }\end{array}$} & \multicolumn{3}{|c|}{$\begin{array}{l}\text { Position } \\
\text { within word }\end{array}$} \\
\hline & & Neologisms & $\begin{array}{l}\text { Misspelled } \\
\text { words }\end{array}$ & $O$ & Ad & $S$ & $C$ & $\boldsymbol{V}$ & $I$ & $M$ & $\boldsymbol{F}$ \\
\hline $\begin{array}{l}\text { Pure agraphia } \\
\text { Agraphia with mild alexia } \\
\text { Agraphia with mild fluent aphasia }\end{array}$ & $\begin{array}{l}\text { W1 } \\
\text { W2 } \\
\text { W3 } \\
\text { W4 } \\
\text { W5 } \\
\text { w6 } \\
\text { W7 }\end{array}$ & $\begin{array}{l}3 \\
\overline{2} \\
- \\
- \\
3 \\
5\end{array}$ & $\begin{array}{l}6 \\
4 \\
8 \\
9 \\
7 \\
7 \\
5\end{array}$ & $\begin{array}{l}5 \\
1 \\
9 \\
8 \\
2 \\
5 \\
7\end{array}$ & $\begin{array}{l}1 \\
1 \\
3 \\
6 \\
6 \\
3\end{array}$ & $\begin{array}{r}12 \\
4 \\
5 \\
11 \\
7 \\
7 \\
5\end{array}$ & $\begin{array}{r}14 \\
1 \\
7 \\
4 \\
5 \\
6 \\
5\end{array}$ & $\begin{array}{r}13 \\
4 \\
7 \\
15 \\
4 \\
6 \\
7\end{array}$ & $\begin{array}{l}6 \\
1 \\
3 \\
4 \\
5 \\
5 \\
2\end{array}$ & $\begin{array}{l}5 \\
3 \\
4 \\
7 \\
5 \\
6 \\
4\end{array}$ & $\begin{array}{l}1 \\
1 \\
2 \\
5 \\
1 \\
2 \\
2\end{array}$ \\
\hline & $\begin{array}{l}\text { Total } \\
\%\end{array}$ & & & $\begin{array}{l}37 \\
35\end{array}$ & $\begin{array}{l}20 \\
18\end{array}$ & $\begin{array}{l}51 \\
47\end{array}$ & $\begin{array}{l}42 \\
43\end{array}$ & $\begin{array}{l}56 \\
57\end{array}$ & $\begin{array}{l}26 \\
35\end{array}$ & $\begin{array}{l}34 \\
46\end{array}$ & $\begin{array}{l}14 \\
19\end{array}$ \\
\hline
\end{tabular}

$\mathbf{O}=$ omissions; $\mathbf{A d}=$ additions; $\mathbf{S}=$ substitutions; $\mathbf{C}=$ consonant; $\mathrm{V}=$ vowel $\mathbf{I}=$ initial $; \mathbf{M}=$ middle; $\mathbf{F}=$ final. 
PURE ANARTHRIA

The analysis of cases with selective impairment of oral expression confirms the generally accepted view that, after a stroke, anarthria may occur in a remarkably isolated state with respect to other language defects. This condition is extremely rare (three cases in 500), as maintained by Souques (1928). As Dejerine (1914) pointed out, pure anarthria may be found both immediately after the stroke (as in case 01) and long after it (as in cases 02 and 03); in the latter event, it is possible that it is a residual symptom of Broca's aphasia. The continuity between pure anarthria and Broca's aphasia is also suggested by the existence of cases of Broca's aphasia with particularly severe anarthria, in contrast with relatively good writing (cases 04 and 05).

The core of pure anarthria, as seen in our patients, consists of an unique combination of linguistic errors (phonemic omissions, substitutions, methatheses, assimilations and so on) and articulatory disorders (particularly depending on weakness of the articulatory muscles). The resulting speech pattern corresponds, in a general way, to the classic descriptions of this conditions (see Alajouanine et al. (1939) and Lecours and Lhermitte (1976) for a summary of the traditional concepts). The mechanism of this disorder is still obscure. It certainly cannot be attributed to oral apraxia, which was absent in one case out of three. On the other hand, the associated presence of rapidly uttered speech (case 02) and aphonia (case 03) stresses the need for further studies focusing on the possible subtypes of this syndrome and on its precise boundaries with purely dysarthric or dysphonic disorders or both.

Little can be said about the intrahemispheric locus of the lesion responsible for pure anarthria in our cases, except that the neurological and neuropsychological evidence pointed to centralanterior lesions-whether cortical, subcortical, or both we do not know.

\section{FLUENT APHASIA WITH RELATIVE SPARING OF}

\section{WRITING}

Sparing of writing in fluent aphasia is a most unusual phenomenon. Occasional descriptions of such dissociation have been given by Head (1926) and Alajouanine and Lhermitte (1960). In his review of the literature on the agraphias up to 1969, Leischner did mention this possibility, but did not discuss its implications in terms of either mechanism or localisation. To our knowledge, the first detailed report of this dissociation is the 1974 paper by Lhermitte and Derouesné. They described two remarkable cases, one with a cerebro- vascular accident in the left Sylvian region and the other with a closed head injury; both of them had mainly phonemic paraphasias and neologisms in oral expression, while writing was distinctly better than speech. A similar discrepancy has been reported recently by Hier and Mohr (1977) in a patient who developed fluent, nonphonemic paraphasic speech with relative sparing of written naming, after an episode of necrotising temporal lobe encephalitis.

The nature of the lesion in Lhermitte and Derouesné's cases did not permit a more precise assessment of its intrahemispheric localisation, while in Hier and Mohr's patient a CT scan showed an extensive temporal lobe lesion and some atrophy in the region of the right Sylvian fissure. Our cases may contribute some information to this point, at least in a negative way. In both of them the lesions involved the left temporal lobe, either at the anterior (case 06) or inferior (07) border of Wernicke's area, and they spared the posterior and superior marginal areas in the parietal lobe. Although caution is necessary in interpreting the localisation of tumour lesions, we feel that one can safely state that the brain damage in our cases entirely spared the posterior and superior marginal areas of the language zone in the parietal lobe. The point we wish to stress is the association of relative integrity of writing with integrity of such parietal areas. We shall come back to the possible meaning of this association when discussing the localisation of lesions producing selective impairment of writing.

\section{PURE AGRAPHIA}

Patients W1 and W2 demonstrate that a focal lesion of the left (dominant) hemisphere can produce an isolated agraphia without other language disorders. The nature of this extremely rare defect (two cases in 500) is open to discussion. Unfortunately, the obvious limitations of a large retrospective survey such as this (for example, lack of systematic information about writing with right and left hand, typing, spelling aloud and so on) prevents us from discussing the disconnection mechanisms hypothesised by Geschwind and coworkers (Heilman et al., 1973, 1974). Likewise, we cannot say whether or not other components of the Gerstmann syndrome were present to a significant degree. In spite of these drawbacks, a few simple points can be made.

In the first place, the absence of other aphasic disorders must be stressed: the only detectable abnormalities of speech were occasional hesitations during oral description in patient $\mathrm{W} 1$ and one single anomia throughout the entire examina- 
tion in W2. Writing errors, however, were essentially linguistic, in the form of neologisms and misspellings, while limb and finger apraxia (at least, on imitation) were consistently absent. These findings, in our view, support the notion that pure agraphia does not depend upon impairment of movement or gesture, but is a selective disorder of language output.

In the second place, the hypothesis, advanced by Chédru and Geschwind (1972a, b) is worth verifying. These authors maintain that often isolated agraphia may not be attributable to focal lesions, but is, in many cases, rather the result of confusional states defined as "reduction and/or ready shifting of attention." The following recorded clinical aspects of our patients have been considered to be indirect clues to a possible diffuse involvement of the left hemisphere, entailing an attention disorder. General clues: dementia (as expressed by poor WAIS score), space-occupying lesions with evidence of raised intracranial pressure, and writing examined shortly after the onset of brain damage. Specific clues: omissions of letters at the end of the word and perseverations in writing to command. These were the most common writing errors that Chédru and Geschwind found to be associated with mild confusion. The results were inconclusive. Case W1 did show perseveration in writing to command and had a particularly low nonverbal IQ, but his verbal IQ was as expected (93). Both W1 and W2 had spaceoccupying lesions; however, these had been removed 14 weeks (W1) and four weeks (W2) before the language examination, leaving no signs of raised intracranial pressure. Moreover, the fact that letter substitutions were more frequent than omissions, and that the middle or initial parts of the word were more often altered than the final part, points to a specific encoding disorder, rather than to an unspecific consequence of defective attention. Therefore, while diffuse brain disorder may perhaps have contributed to some aspects of pure agraphia (such as perseverations in W1), it certainly cannot be held responsible for the bulk of this disorder. On the contrary, the available evidence suggests that, in our cases, the isolated writing defect was due to a particular localisation of the cerebral lesion-that is, to damage of the superior and posterior parietal areas of the left hemisphere. These areas were damaged in the two patients with posterior lesions (W1 and W2) whose writing was selectively impaired; conversely, they were intact in the two patients with posterior lesions (06 and 07) whose writing was selectively spared. As the two "groups" were quite comparable with respect to other clinical variables (see
Table 2 and 3), this double dissociation probably reflects the different locus of lesion within the left hemisphere. It is noteworthy that in the one other patient whose lesion could be localised (W3), severe agraphia with mild alexia was also associated with a posterior parietal lesion.

The notion that damage to the upper posterior parietal lobe is crucial in producing a selective disorder of writing is supported by a number of published findings (for example, Marie et al., 1917), and has been explicitly stated by Russell and Espir (1961). They reported the "surprising" finding of a small group of gunshot wounds causing relatively pure agraphia through deep parasagittal lesions of the left posterior parietal lobe, and they pointed out that "this area of the brain is very much concerned with those correlations of body image and spatial orientation which may lead to apraxia and other remarkable parietal lobe syndromes." Indeed, the association between agraphia without other language defects and lesions of the upper posterior parietal lobe is often found in the records of cases that have been published as outstanding examples of other neuropsychological disorders, such as the patients with autotopagnosia described by De Renzi and Faglioni (1963) and De Renzi and Scotti (1970). At any rate, the hypothesis may be advanced that the posterior superior left parietal lobule in man is crucial for the sensorimotor linguistic integration needed for writing. The question deserves further study.

We wish to thank Dr Norman Geschwind for his helpful advice on the manuscript.

\section{References}

Alajouanine, T., and Lhermitte, F. (1960). Les troubles des activités expressives du langage dans l'aphasie. Leurs relations avec l'aphasie. Revue Neurologique, 102, 604-629.

Alajouanine, T., Ombrédane, A., and Durand, M. (1939). Le Syndrôme de Désintégration Phonétique dans l'A phasie. Masson: Paris.

Chédru, F., and Geschwind, N. (1972a). Disorders of higher cortical functions in acute confusional states. Cortex, 8, 395-411.

Chédru, F., and Geschwind, N. (1972b). Writing disturbances in acute confusional states. Neuropsychologia, 10, 343-353.

Dejerine, J. (1914). Sémiologie des Affections du Système Nerveux. Masson: Paris.

De Renzi, E., and Faglioni, P. (1963). L'autotopoagnosia. Archivio di Psicologia, Neurologia $e$ Psichiatria, 24, 1-34.

De Renzi, E., and Scotti, G. (1970). Autotopognosia: 
fiction or reality? Archives of Neurology (Chicago), 23, 221-227.

Head, H. (1926). A phasia and Kindred Disorders of Speech. Cambridge University Press: London.

Heilman, K. M., Coyle, J. M., Gonyea, E. F., and Geschwind, N. (1973). Apraxia and agraphia in a left-hander. Brain, 96, 21-28.

Heilman, K. M., Gonyea, E. F., and Geschwind, N. (1974). Apraxia and agraphia in a right-hander. Cortex, 10, 284-288.

Hier, D. B., and Mohr, J. P. (1977). Incongruous oral and written naming. Evidence for a subdivision of the syndrome of Wernicke's aphasia. Brain and Language, 4, 115-126.

Leischner, A. (1969). The agraphias. In Handbook of Clinical Neurology. Edited by P. G. Vinken and G. W. Bruyn, Vol. 4. North-Holland Publishing Co: Amsterdam.
Lecours, A. R., and Lhermitte, F. (1976). The "pure form" of the phonetic disintegration syndrome (pure anarthria); anatomo-clinical report of a historical case. Brain and Language, 3, 88-113.

Lhermitte, F., and Derouesné, J. (1974). Paraphasies et jargonaphasie dans le langage oral. Revue Neuro. logique, 130, 21-38

Marie, P., Foix, Ch., and Bertrand, I. (1917). Les aphasies de guerre. Revue Neurologique, 1, 3-18.

Russel, W. R., and Espir, M. L. E. (1961). Traumatic Aphasia. Oxford University Press: London.

Souques, A. (1928). Quelques cas d'anarthrie de Pierre Marie. Revue Neurologique, 2, 319-430.

Tissot, A., Rodriguez, J., and Tissot, R. (1970). Die Prognose der Anarthrie im Sinne von Pierre Marie. In Die Rehabilitation der Aphasie in den Romanischen Ländern. Edited by A. Leischner. Georg Thieme: Stuttgart. 